ARTICLE

\title{
Control of zeolite microenvironment for propene synthesis from methanol
}

Longfei Lin (1) 1, Mengtian Fan', Alena M. Sheveleva (1) 1,2, Xue Han', Zhimou Tang ${ }^{3}$, Joseph H. Carter (1) 1,4, Ivan da Silva (1) 5, Christopher M. A. Parlett (1) 4,6,7,8, Floriana Tuna (1) 1,2, Eric J. L. Mclnnes (1) 1,2, German Sastre (10) 9, Svemir Rudić (10 5 , Hamish Cavaye (1) ${ }^{5}$, Stewart F. Parker (1) 5,8, Yongqiang Cheng ${ }^{10}$, Luke L. Daemen ${ }^{10}$, Anibal J. Ramirez-Cuesta (10 ${ }^{10}$, Martin P. Attfield (10) ${ }^{1}$, Yueming Liu ${ }^{3}$, Chiu C. Tang ${ }^{4}$, Buxing Han (1) ${ }^{11} \&$ Sihai Yang (10) ${ }^{1 凶}$

Optimising the balance between propene selectivity, propene/ethene ratio and catalytic stability and unravelling the explicit mechanism on formation of the first carbon-carbon bond are challenging goals of great importance in state-of-the-art methanol-to-olefin (MTO) research. We report a strategy to finely control the nature of active sites within the pores of commercial MFI-zeolites by incorporating tantalum(V) and aluminium(III) centres into the framework. The resultant TaAIS-1 zeolite exhibits simultaneously remarkable propene selectivity (51\%), propene/ethene ratio ( 8.3 ) and catalytic stability $(>50 \mathrm{~h})$ at full methanol conversion. In situ synchrotron X-ray powder diffraction, X-ray absorption spectroscopy and inelastic neutron scattering coupled with DFT calculations reveal that the first carbon-carbon bond is formed between an activated methanol molecule and a trimethyloxonium intermediate. The unprecedented cooperativity between tantalum( $\mathrm{V})$ and Brønsted acid sites creates an optimal microenvironment for efficient conversion of methanol and thus greatly promotes the application of zeolites in the sustainable manufacturing of light olefins.

\footnotetext{
${ }^{1}$ Department of Chemistry, University of Manchester, Manchester, UK. ${ }^{2}$ Photon Science Institute, University of Manchester, Manchester, UK. ${ }^{3}$ Shanghai Key Laboratory of Green Chemistry and Chemical Processes, School of Chemistry and Molecular Engineering, East China Normal University, Shanghai, China. ${ }^{4}$ Diamond Light Source, Harwell Science and Innovation Campus, Didcot, Oxfordshire, UK. ${ }^{5}$ ISIS Facility, STFC Rutherford Appleton Laboratory, Chilton, Oxfordshire, UK. ${ }^{6}$ Department of Chemical Engineering and Analytical Science, University of Manchester, Manchester, UK. ${ }^{7}$ University of Manchester at Harwell, Diamond Light Source, Didcot, Oxfordshire, UK. ${ }^{8}$ UK Catalysis Hub, Research Complex at Harwell, Didcot, Oxfordshire, UK. ${ }^{9}$ Instituto de Tecnologia Quimica, UPV-CSIC Universidad Politecnica de Valencia, Valencia, Spain. ${ }^{10}$ Neutron Scattering Division, Oak Ridge National Laboratory, Oak Ridge, TN, USA.

${ }^{11}$ Beijing National Laboratory for Molecular Sciences, CAS Key Laboratory of Colloid, Interface and Chemical Thermodynamics, Institute of Chemistry,

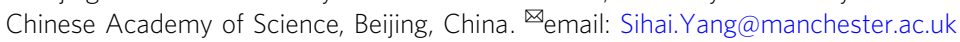


P ropene is mass produced as a key light olefin for the synthesis of a wide spectrum of vital polymers and fine chemicals ${ }^{1}$. However, a global propene shortage is predicted $^{2-4}$ (supply vs. demand is 85 vs. 118 million tonnes in 2021) due to the rapidly growing demand for propene (projected propene market will reach $\$ 137$ billion by 2027) alongside the low propene $(\mathrm{P}) /$ ethene $(\mathrm{E})$ ratio (typically $\mathrm{P} / \mathrm{E}<1$ ) that is achieved in the state-of-the-art naphtha cracking processes. Methanol-toolefins (MTO) processes ${ }^{5-12}$ can mitigate this short fall so have received tremendous interest from both academia and industry because they enable the production of light olefins from methanol, a feedstock widely obtainable from biomass, waste, coal, natural gas and even carbon dioxide ${ }^{13}$, that will enable future sustainable manufacturing processes. Commercial MTO plants use ZSM-5 and SAPO-34 zeolites as catalysts and yield multiple products via complex, and still debated reaction pathways ${ }^{5,10}$. More than 20 different, sometimes controversial, formation mechanisms of the first carbon-carbon bond have been postulated to date, including the carbene mechanism ${ }^{14}$, the methane-formaldehyde mechanism ${ }^{15}$, the methyleneoxy mechanism $^{16}$, the methoxymethyl cation mechanism ${ }^{17}$, the Koch carbonylation mechanism ${ }^{18}$, and the methane-Al/oxonium mechanism ${ }^{19}$. Thus, understanding the precise reaction mechanism and developing efficient catalysts that achieve the optimal balance between propene selectivity, $\mathrm{P} / \mathrm{E}$ ratio and catalytic stability in MTO processes remain unsolved problems ${ }^{20}$.

Current top-performing MTO catalysts include: M-ZSM-5 (M $=\mathrm{Mg}, \mathrm{Ca}, \mathrm{Sr}$ ) affording propene selectivities of $38-51 \%, \mathrm{P} / \mathrm{E}$ ratios of 3.3-6.8 and catalyst lifetime of 24-95 h6; high-silica Beta zeolite exhibiting a high propene selectivity of $58 \%$, a $\mathrm{P} / \mathrm{E}$ ratio of 9.8 and catalyst lifetime of $23 \mathrm{~h}^{11}$; RUB- 13 zeolite with precise cage cavity showing propene selectivity of $45 \%, \mathrm{P} / \mathrm{E}$ ratio of 3.0 and lifetime of $11 \mathrm{~h}$ at $95 \%$ conversion of methanol ${ }^{8}$; CON-type zeolite giving high propene selectivity of $60 \%$ and lifetime of $25 \mathrm{~h}$, but a low P/E ratio of $2.7^{21}$; SAPO-14 zeolites with small pores exhibiting high propene selectivity of $66 \%$ and $\mathrm{P} / \mathrm{E}$ ratio of 4.1 at full conversion of methanol, but having a short lifetime of $\sim 0.3 \mathrm{~h}^{9}$. Small pore catalysts generally suffer from severe deactivation due to the rapid blockage of pores by coke. Considering all three indexes, i.e., propene selectivity-P/E ratio-catalytic stability, Ca-ZSM-5 and high-silica Beta zeolite are promising candidates for catalysing MTO reactions (Fig. 1), while new zeolites, other than ZSM-5 and SAPO-34, have yet to be commercialised owing to the uncertainty around their large-scale synthesis and applicability in the existing industrial infrastructure.

We have recently developed a Nb-containing zeolite 22 which shows excellent performance in the cleavage of $\mathrm{C}-\mathrm{O}$ bonds in $\gamma$ valerolactone via its efficient activation over $\mathrm{Nb}(\mathrm{V})$ sites. However, the weak acidity of this material restricts the formation of carbon-carbon bonds in MTO reactions with a nil $(<1 \%)$ selectivity to olefins (Supplementary Table 1). Tantalum is extremely electrophilic and can drive the formation and cleavage of carbon-carbon bonds during the metathesis of alkanes ${ }^{23}$. However, its catalytic performance in MTO reactions has not been explored and the precise catalytic role of tantalum remains unclear. Here we report control of the microenvironment of ZSM-5 via incorporating $\mathrm{Ta}(\mathrm{V})$ and $\mathrm{Al}(\mathrm{III})$ centres into the framework to afford a new hetero-atomic zeolite (denoted as TaAlS1) to achieve simultaneously high propene selectivity ( $>50 \%), \mathrm{P} / \mathrm{E}$ ratios (up to 11 ) and high stability $(>50 \mathrm{~h}$ ) in MTO process. A series of operando studies employing synchrotron X-ray diffraction and absorption spectroscopy and neutron spectroscopy confirm that an unprecedented cooperativity between $\mathrm{Ta}(\mathrm{V})$ and Brønsted acid sites results in efficient activation of adsorbed methanol and the formation of trimethyloxonium (TMO) intermediate species, thereby promoting the formation of the first

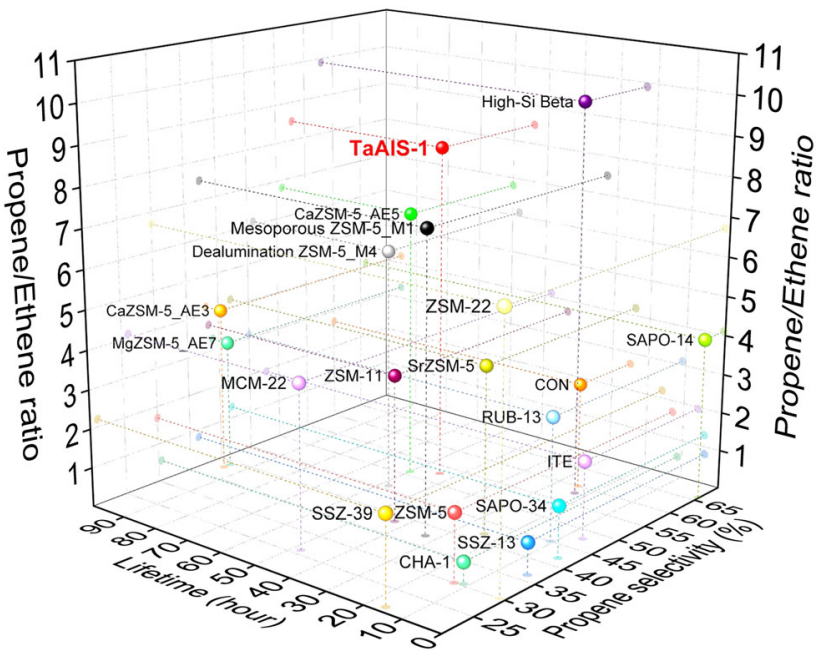

Fig. 1 Comparison of propene selectivity-propene/ethene ratio-catalytic stability of selected MTO catalysts. 3D plot of $P / E$ ratio versus lifetime and propene selectivity, showing the balance of catalytic performance of selected zeolites for conversion of pure methanol to olefins at methanol conversion $\geq 95 \%$. For clarity, only representative zeolites are shown in the plot. Full data are listed in Supplementary Table 1.

carbon-carbon bond in propene. The multifunctional microenvironment of TaAlS-1 has enabled effective control of product selectivity while sustaining the high catalytic stability of ZSM-5, thus reinforcing its potential for the production of propene from methanol.

\section{Results}

Synthesis and characterisation. A range of ZSM-5 samples containing $\mathrm{Ta}(\mathrm{V})(0-3.7 \mathrm{wt} \%)$ and $\mathrm{Al}(\mathrm{III})$ (0-1.1 wt\%) were synthesised by hydrothermal reactions. All obtained materials exhibit the MFI-type framework (Supplementary Fig. 1), Brunauer-Emmett-Teller (BET) surface areas of $402-429 \mathrm{~m}^{2} \mathrm{~g}^{-1}$ (Supplementary Table 2), and particle size distributions of 300-500 nm (Supplementary Fig. 2, Supplementary Table 2). The atomic ratio of $\mathrm{Ta} / \mathrm{Al} / \mathrm{Si}$ was determined by energy-dispersive $\mathrm{X}$ ray (EDX) analysis, which confirmed the existence of metal sites in the zeolites (Fig. 2a, b, Supplementary Fig. 3). The vibrational modes of Ta-O-Si moieties in TaAlS-1(0.013/0.027/1) are observed by FTIR at $960 \mathrm{~cm}^{-1}$ (Fig. 2c) and a transition at 220 $\mathrm{nm}$ observed in the UV-vis spectrum of TaAlS-1(0.013/0.027/1) (Fig. 2d), indicating the incorporation of $\mathrm{Ta}(\mathrm{V})$ centres at framework $\mathrm{T}$-sites and the absence of aggregation of $\mathrm{Ta}(\mathrm{V})$ sites. The ${ }^{27} \mathrm{Al}$ NMR spectrum of TaAlS-1(0.013/0.027/1) shows that $\mathrm{Al}(\mathrm{III})$ centres are incorporated into the framework with an absence of $\mathrm{Al}_{2} \mathrm{O}_{3}$ (Supplementary Fig. 4).

Electron paramagnetic resonance (EPR) spectroscopy has also confirmed the successful incorporation of $\mathrm{Ta}(\mathrm{V})$ and $\mathrm{Al}(\mathrm{III})$ into framework sites. Although TaS-1 (the isostructural analogue with no $\mathrm{Al}$ ) and TaAlS-1 are EPR silent due to the diamagnetic $\mathrm{Ta}(\mathrm{V})$ and $\mathrm{Al}(\mathrm{III})$ ions, characteristic paramagnetic centres can be induced by $\gamma$-irradiation of the zeolites ${ }^{24}$. Initial signals of $\gamma$ irradiated TaS-1 and TaAlS-1 samples were assigned to electron-hole defects on a framework oxygen atom in $\mathrm{Ta}-\mathrm{O} \cdot-\mathrm{Si}$ sites. The assignment was derived from the analysis of quadrupole and hyperfine coupling with the ${ }^{181} \mathrm{Ta}$ nucleus $(I=7 / 2 ; 99.98 \%$ natural abundance; Fig. 2e and Supplementary Table 3). Saturation of the EPR signal ${ }^{25}$ of TaAlS-1 sample by increasing the microwave power from 7 to $70 \mathrm{~mW}$ revealed the appearance of a characteristic signal for $\mathrm{Al}-\mathrm{O}^{\bullet}-\mathrm{Si}$ sites $^{26}$ (Fig. 2e), which is also confirmed by the Pulse HYSCORE spectroscopy (HYSCORE $=$ 

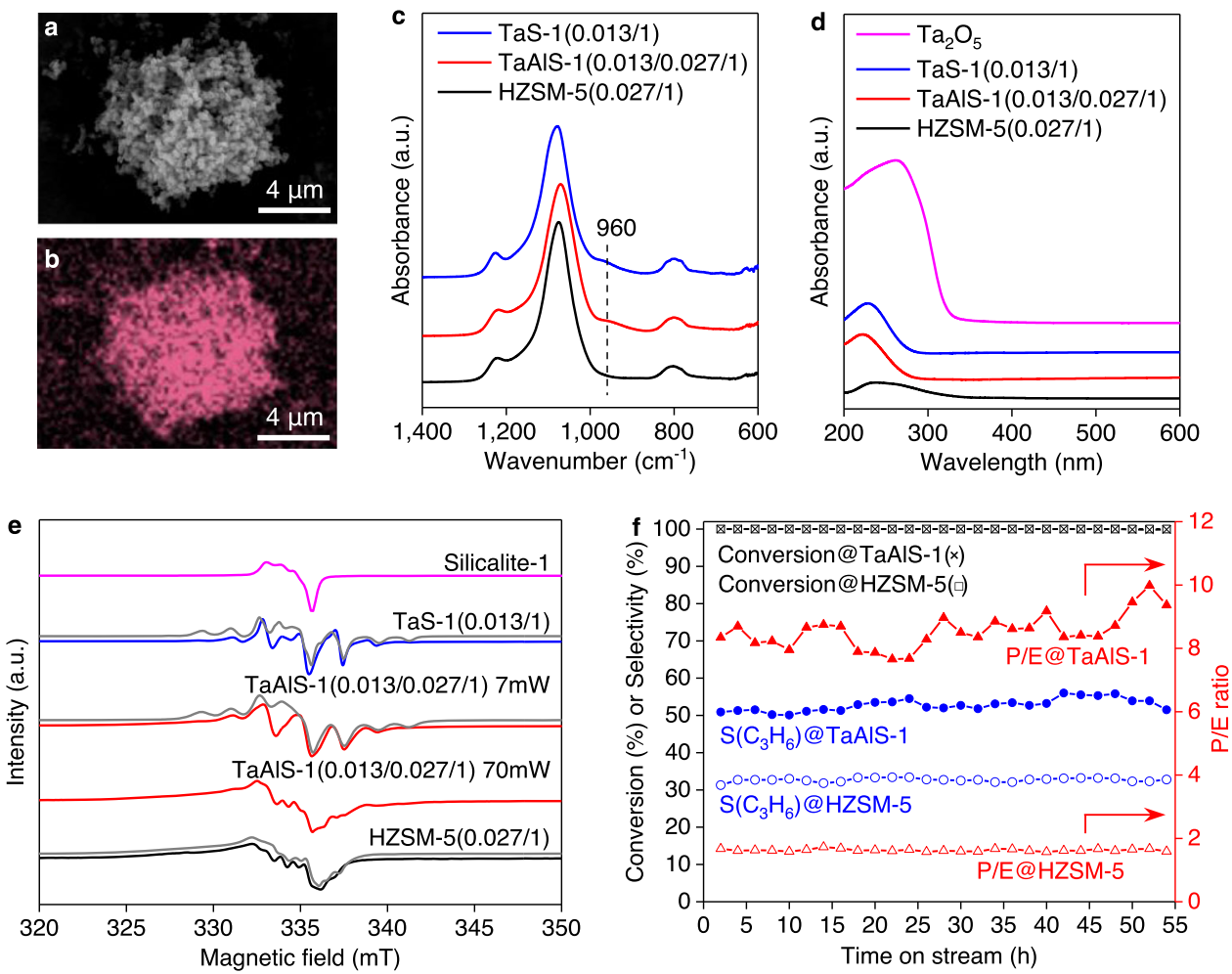

Fig. 2 Physical characterisation and stability of catalysts. a SEM image of TaAIS-1(0.013/0.027/1), b EDX map of Ta $\mathrm{L}_{a}$ in TaAIS-1(0.013/0.027/1). c FTIR and $\mathbf{d}$ UV-vis spectra of HZSM-5(0.027/1), TaAIS-1(0.013/0.027/1) and TaS-1(0.013/1) samples. e X-band (9.4 GHz) CW EPR spectra recorded at $40 \mathrm{~K}$ of vacuum-sealed zeolites activated by $\gamma$-irradiation at $77 \mathrm{~K}$. The spectra of Silicalite-1, TaS- 1 and HZSM- 5 were recorded with a microwave power of $7 \mathrm{~mW}$. Simulated line shapes are shown in grey; parameters for simulation are presented in Supplementary Table 3. f Lifetime study of TaAIS-1(0.013/ $0.027 / 1)$ and $\mathrm{HZSM}-5(0.027 / 1)$ at $400^{\circ} \mathrm{C}$, WHSV $0.16 \mathrm{~h}^{-1} . \mathrm{S}\left(\mathrm{C}_{3} \mathrm{H}_{6}\right)=$ propene selectivity. The yield of propene on TaAIS-1 (0.013/0.027/1) remained at $>50 \%$ after $54 \mathrm{~h}$ of continuous reaction.

hyperfine sub-level correlation; Supplementary Note 1 EPR spectroscopy, Supplementary Fig. 5 and Supplementary Table 4). The signals of $\mathrm{Al}-\mathrm{O}^{\bullet}-\mathrm{Si}$ and $\mathrm{Ta}-\mathrm{O}^{\bullet}-\mathrm{Si}$ defect sites are absent in TaS-1 and HZSM-5 samples, respectively (Supplementary Fig. 6). Thus, EPR measurements provide convincing evidence for the incorporation of both $\mathrm{Ta}(\mathrm{V})$ and $\mathrm{Al}(\mathrm{III})$ centres into the framework of TaAlS-1, enabling the effective control of the active sites within the microenvironment.

The nature of acidity in these zeolites was studied by pyridineadsorption infra-red spectroscopy (Py-IR) and further quantified by ammonia temperature-programmed desorption ( $\mathrm{NH}_{3}$-TPD) (Supplementary Figs. 7 and 8). TaS-1 exhibits solely Lewis acidity due to the presence of $\mathrm{Ta}(\mathrm{V})$, whereas TaAlS-1 shows both Lewis and Brønsted acidity that arises from the dual-functionality of $\mathrm{Ta}$ (V) and Al(III) sites. Notably, the nature of the acidity in TaAlS-1 is distinct from that of HZSM-5: the ratio of Lewis/Brønsted acid sites in TaAlS-1 is 7.8 (Supplementary Table 5), 20 times that of HZSM-5. HZSM-5 displays both strong and weak acid sites with a total amount of $0.39 \mathrm{mmol} \mathrm{g}^{-1}$ and TaS-1 exhibits a minor amount $\left(\sim 0.02 \mathrm{mmol} \mathrm{g}^{-1}\right)$ of weak acid sites. Interestingly, TaAlS-1 shows only weak acid sites, but their concentration is considerably higher $\left(0.18 \mathrm{mmol} \mathrm{g}^{-1}\right)$ than that of TaS-1. Thus, the incorporation of pentavalent tantalum species in the MFIzeolite can directly tune the framework acidity to optimise its catalytic properties.

Catalytic tests. Methanol conversions were performed over a fixed-bed reactor under flow conditions at $400{ }^{\circ} \mathrm{C}$ (Table 1). HZSM-5 with varying $\mathrm{Si} / \mathrm{Al}$ ratios (15-37:1) show full conversions of methanol and moderate propene selectivities of $7.7-31 \%$
(Entries 1-3). Meanwhile, considerable amounts of ethene are produced (up to 19\%). This indicates that both alkene and aromatic cycles (in favour of the formation of propene and ethene, respectively) occur over HZSM-56,27, resulting in low P/E ratios of 1.1-1.7. Moreover, excess alkanes are produced (entries 1-3, 23-70\%) as hydrogen transfer can readily occur over the strong acid sites in HZSM- $5^{28}$. The lack of Brønsted acid sites in TaS-1 leads to very low methanol conversion (5.1-7.5\%) and propene selectivity $(<1 \%)$ with dimethyl ether (DME) as the major product (entries 4 and 5). Similarly, the weak acid sites in NbAlS-122 restrict the formation of carbon-carbon bonds and result in a high selectivity of DME (99\%) at $92 \%$ conversion of methanol (Supplementary Table 1). Interestingly, TaAlS-1 samples show significantly enhanced catalytic performance (entries 6 and 7). TaAlS-1(0.013/0.027/1) shows a high propene selectivity of $51 \%$, a P/E ratio of 8.3 and an excellent time-on-stream stability of over $50 \mathrm{~h}$ at $100 \%$ conversion of methanol (Fig. 2f). A slightly higher propene selectivity of $52 \%$ and $\mathrm{P} / \mathrm{E}$ ratio of 11 were achieved over TaAlS-1(0.008/0.027/1) at a methanol conversion of $97 \%$. These results compare favourably with state-of-the-art catalysts in MTO reactions (Fig. 1, Supplementary Table 1).

It has been widely reported that strong acid sites in zeolite catalysts favour the aromatic cycle to produce ethene, while the alkene cycle occurs on relatively weak acid sites to yield propene ${ }^{27,29}$. The incorporation of $\mathrm{Ta}(\mathrm{V})$ effectively moderates the strong Brønsted acid sites created by $\mathrm{Al}(\mathrm{III})$ sites in TaAlS-1 and thus hinders the aromatic cycle to promote the propene selectivity and $\mathrm{P} / \mathrm{E}$ ratios and slows down the formation of coke. Reduction of $\mathrm{Al}(\mathrm{III})$ sites in TaAlS-1 decreases the acidity (Supplementary Table 5) and leads to the production of DME as the primary product (Table 1 , entry 8 ). However, the distribution 
Table 1 Summary of the methanol conversion and product selectivities over different catalysts in MTO reactionsa.

\begin{tabular}{|c|c|c|c|c|c|c|c|c|c|}
\hline Entry & Catalyst & Conversion (\%) & DME & $\mathrm{C}_{2} \mathrm{H}_{4}$ & $\mathrm{C}_{3} \mathrm{H}_{6}$ & $\mathrm{C}_{4} \mathrm{H}_{8}$ & $\mathrm{C}_{2}{ }^{\mathrm{O}}-\mathrm{C}_{4}{ }^{\mathrm{O} b}$ & Others $^{c}$ & $\mathrm{C}_{3} \mathrm{H}_{6} / \mathrm{C}_{2} \mathrm{H}_{4}$ \\
\hline 1 & HZSM-5(0.027/1) & 100 & 0 & 19 & 31 & 18 & 23 & 8.6 & 1.7 \\
\hline 3 & HZSM-5(0.067/1) & 100 & 0 & 7.0 & 7.7 & 2.8 & 70 & 12 & 1.1 \\
\hline 4 & TaS-1(0.008/1) & 5.1 & $>99$ & $<0.1$ & 0.4 & 0 & 0 & 0 & - \\
\hline 5 & TaS-1(0.013/1) & 7.5 & $>99$ & $<0.1$ & 0.7 & 0 & 0 & 0 & - \\
\hline 8 & TaAIS-1(0.013/0.02/1) & 86 & 64 & 2.9 & 18 & 10 & 1.2 & 3.6 & 6.1 \\
\hline 9 & TaAIS-1(0.013/0.013/1) & 20 & 93 & $<0.1$ & 1.9 & 2.7 & 0.1 & 2.4 & - \\
\hline 10 & $\mathrm{Ta}_{2} \mathrm{O}_{5} / \mathrm{HZSM}-5(0.027 / 1)^{\mathrm{d}}$ & 100 & 0 & 20 & 33 & 19 & 23 & 6.1 & 1.7 \\
\hline
\end{tabular}

of propene among hydrocarbons produced over TaAlS- $1(0.013 /$ $0.02 / 1$ ) is $50.4 \%$ (Table 1 , entry 8 ), which is similar to that obtained over TaAlS-1(0.013/0.027/1). This result suggests that over TaAlS-1(0.013/0.02/1), the conversion of DME to olefins is significantly hindered, while the transformation of ethene to higher olefins is affected to a less extent, further indicating that the formation of the first carbon-carbon is the limiting step. Further reduction of $\mathrm{Al}(\mathrm{III})$ sites restricts the formation of first carbon-carbon bonds and hence the following reactions, leading to the low selectivity of propene (Table 1, entry 9). Thus, a suitable amount of $\mathrm{Al}(\mathrm{III})$ sites is essential for the production of propene. The powdered mixture of $\mathrm{Ta}_{2} \mathrm{O}_{5}$ and HZSM-5 shows similar activity to that of HZSM-5, indicating that the cooperativity between $\mathrm{Ta}(\mathrm{V})$ and Brønsted acid sites within the microenvironment is vital (Table 1 , entry 10). The time-onstream test on TaAlS-1(0.013/0.027/1) at conversion of $94 \%$ showed that the conversion decreased rapidly (Supplementary Figs. 9-12). This is likely due to the promoted pathway of hydrogen transfer over Lewis and Brønsted acid sites in the presence of methanol, leading to rapid coke formation ${ }^{28}$. However, at full conversion, the activity remains intact for $54 \mathrm{~h}$ and the used catalyst shows only minor difference in the textual properties (Fig. 2f and Supplementary Table 2, Supplementary Figs. 13 and 14), demonstrating the excellent stability of this bifunctional zeolite. Overall, these results suggest that the strength, nature and distribution of the active sites are key parameters for optimising the MTO catalyst.

Determination of adsorption domains for methanol. In situ synchrotron X-ray powder diffraction (SXPD) study (Supplementary Figs. 15-17, Supplementary Tables 6-13) determined four binding sites of methanol molecules (denoted as I-IV; Fig. 3) within the pores. Adsorbed methanol molecules show three distinct spatial orientations within the pores of TaAlS-1, HZSM-5 and TaS-1 (Fig. 3a-c, Supplementary Note 2 Interaction between methanol and $\mathrm{Ta} / \mathrm{Al} / \mathrm{H}$ sites). $\mathrm{MeOH}^{\mathrm{II}}$ and $\mathrm{MeOH}^{\mathrm{IV}}$ are located within the straight and sinusoidal channels of TaAlS-1, interacting with bridging $\mathrm{O}(\mathrm{H})$-centres through their $\mathrm{C}-\mathrm{OH}$ groups via hydrogen bonds [C-O $\cdots \mathrm{O}=3.025,3.725 \AA$, respectively] (Fig. 3d, Supplementary Fig. 17a). $\mathrm{MeOH}^{\mathrm{I}}$ resides between $\mathrm{MeOH}^{\mathrm{II}}$ and $\mathrm{MeOH}^{\mathrm{IV}}\left[\mathrm{C}^{\mathrm{IV}} \cdots \mathrm{O}^{\mathrm{I}}=2.972 \AA, \mathrm{C}^{\mathrm{II}} \ldots \mathrm{O}^{\mathrm{I}}=3.476\right.$ $\AA$ ] and this assembles a $\{\mathrm{MeOH}\}_{3}$ trimer that favours the formation of TMO as the reaction intermediate ${ }^{16}$. The TMO-type configuration is also observed in HZSM-5 (Fig. 3e), but not in TaS-1 due to lack of Brønsted acid sites (Fig. 3f). Interestingly, a previous SXPD study on the adsorption of $\mathrm{MeOH}$ vapour in
HZSM-5 has revealed that one $\mathrm{MeOH}$ molecule adsorbed on the Brønsted acid site $[\mathrm{C}-\mathrm{O} \cdots \mathrm{O}=2.910 \AA]$ and a second $\mathrm{MeOH}$ molecule resided nearby ${ }^{30} \cdot \overline{\mathrm{MeOH}}^{\mathrm{III}}$ is located close to $\mathrm{MeOH}^{\mathrm{IV}}$ in both TaAlS-1 and HZSM-5 $\left[\mathrm{C}^{\mathrm{IV}} \ldots \mathrm{C}^{\mathrm{III}}=2.787,2.701 \AA\right.$ respectively] (Fig. 3g, h, Supplementary Fig. 17b), and it interacts with $\mathrm{Ta}(\mathrm{V})$ sites in TaAlS-1 [O $\left.{ }^{\mathrm{III}} \ldots \mathrm{T} 5=3.992 \AA\right]$, which is potentially crucial for the activation of the $\mathrm{C}-\mathrm{O}$ bond and thus to the formation of the first $\mathrm{C}-\mathrm{C}$ bond. ${ }^{29} \mathrm{Si} \mathrm{NMR}$, inelastic neutron scattering (INS) and DFT calculations ${ }^{22,31,32}$ demonstrate that TaAlS-1 (0.013/0.027/1) has an optimal site distribution (Supplementary Figs. 18-20, Supplementary Tables 14-17, and Supplementary Note 3 Distribution of $\mathrm{Ta} / \mathrm{Al} / \mathrm{H}$ sites) that promotes the adsorption of methanol in TaAlS-1 via a "TMO-type" mechanism, highly consistent with the SXPD analysis and the excellent catalytic performance. In TaS-1, MeOH ${ }^{\mathrm{III}}$ hardly interacts with $\mathrm{MeOH}^{\mathrm{IV}}\left[\mathrm{C}^{\mathrm{IV}} \ldots \mathrm{C}^{\mathrm{III}}=4.127 \AA\right]$ (Fig. 3i), again consistent with the catalysis result. Thus, the excellent catalytic activity of TaAlS-1 originates from (i) the highly confined adsorption of methanol over Brønsted acid sites to form TMOtype moieties in the pores; (ii) the efficient activation of $\mathrm{C}-\mathrm{O}$ bonds in additional methanol molecules adsorbed over $\mathrm{Ta}(\mathrm{V})$ sites.

Studies of the coordination environment of $\mathrm{Ta}(\mathrm{V})$ sites. The local environment of the active $\mathrm{Ta}(\mathrm{V})$ site was interrogated through Ta L3-edge X-ray absorption spectroscopy (XAS; Fig. 4a, b, Supplementary Figs. 21-26). The absorption edge peak positions of TaS-1 and TaAlS-1 (Fig. 4a) are consistent with $\mathrm{Ta}(\mathrm{V})$ oxidation state $\mathrm{s}^{33}$, and the framework species are stable to the activation process employed prior to catalytic studies. Interestingly, dry TaAlS-1 shows an increase in the white line intensity (at $9886 \mathrm{eV}$ originating from $2 p_{3 / 2} \rightarrow 5 d$ transition $^{34}$ ) relative to dry TaS-1 (Fig. 4b), representing a partial decrease in $5 d$-orbital filling. This arises from the charge imbalance resulting from framework $\mathrm{Al}(\mathrm{III})-\mathrm{O}-\mathrm{Si}$ species, consistent with the Py-IR analysis which shows increased Lewis acidity in TaAlS-1 relative to that of TaS-1 (Supplementary Fig. 7). This disparity in $d$-orbital occupancy of the $\mathrm{Ta}(\mathrm{V})$ sites influences the interaction with methanol. In TaAlS-1, adsorbed methanol interacts with the Ta (V) site by donating electrons to the $\mathrm{Ta}(\mathrm{V}) d$-orbital, as evidenced by the decrease in white line intensity (Fig. 4b), whereas in TaS-1 methanol accepts electrons resulting in the increase in white line intensity (Fig. 4b). This observation concurs with SXPD results, which clearly show different geometries of adsorbed methanol on TaAlS-1 and TaS-1 (Fig. 3). Thus, introduction of $\mathrm{Ta}(\mathrm{V})$ into the 

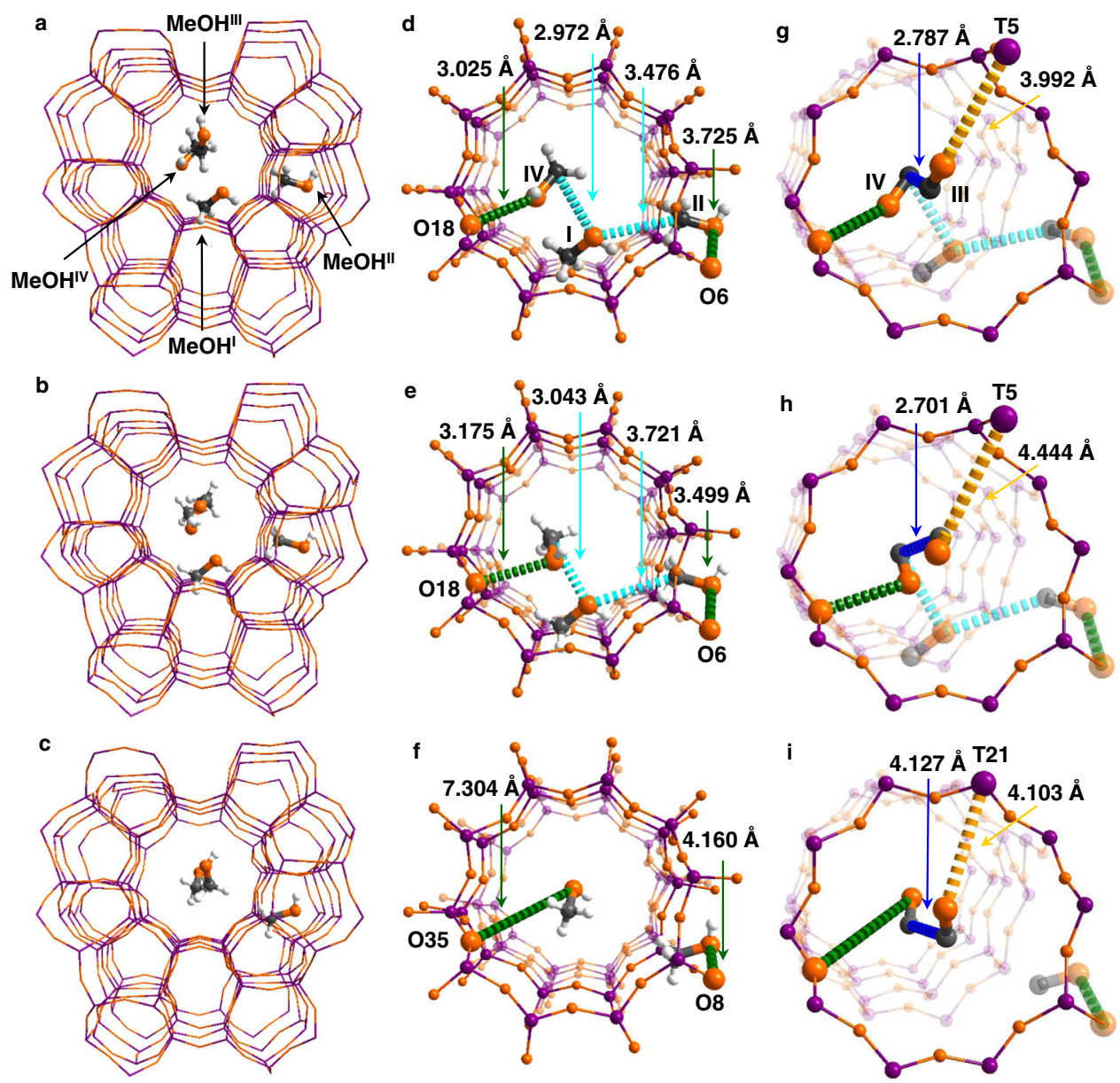

Fig. 3 Views of crystal structures of MeOH-loaded TaAIS-1(0.013/0.027/1), HZSM-5(0.027/1) and TaS-1(0.013/1). All models were obtained from Rietveld refinements of SXPD data. Four distinct binding sites (I-IV) for $\mathrm{MeOH}$ have been observed in the straight and sinusoidal channels. a TaAIS-1 $(0.013 / 0.027 / 1) \cdot 8.6 \mathrm{MeOH}\left(\mathrm{Al}_{2.5} \mathrm{Ta}_{1.2} \mathrm{Si}_{92.3} \mathrm{O}_{192} \cdot 8.6 \mathrm{CH}_{4} \mathrm{O}\right)$, b HZSM-5(0.027/1)·12.3MeOH $\left(\mathrm{Al}_{2.5} \mathrm{Si}_{93.5} \mathrm{O}_{192} \cdot 12.3 \mathrm{CH} \mathrm{H}_{4} \mathrm{O}\right) \cdot \mathbf{c} \mathrm{TaS}-1(0.013 / 1) \cdot 4.0 \mathrm{MeOH}$

$\left(\mathrm{Ta}_{1.2} \mathrm{Si}_{94.8} \mathrm{O}_{192} \cdot 4.0 \mathrm{CH}_{4} \mathrm{O}\right)$. Only three binding sites were observed in TaS-1. The details of the host-guest binding are enlarged in $\mathbf{d}-\mathbf{i}$. Detailed views of $\mathrm{MeOH}^{\mathrm{I}, \mathrm{II}, \mathrm{IV}} \mathbf{d}-\mathbf{f}$ and $\mathrm{MeOH}^{\mathrm{III}} \mathbf{g}-\mathbf{i}$ in TaAIS-1(0.013/0.027/1), HZSM-5(0.027/1) and TaS-1(0.013/1), respectively. MeOH molecules and the functional sites involved in the cooperative binding are highlighted using an amplified ball-and-stick model ( $\mathrm{Ta} / \mathrm{Al} / \mathrm{Si}$, violet; $\mathrm{C}$, grey; $\mathrm{O}$, orange; $\mathrm{H}$, white). The $\mathrm{O}$... $\mathrm{O}(\mathrm{H})$ interactions and $\mathrm{O} \cdots \mathrm{Ta}$ interactions are highlighted in green and yellow, respectively. The $\mathrm{C} \cdots \mathrm{O}$ distances and $\mathrm{C} \cdots \mathrm{C}$ distances are highlighted in cyan and blue, respectively. Owing to the uncertainty on locations of protons, all hydrogen bonds in this report are described as the distance between the $\mathrm{O}_{\mathrm{MeOH}}$ and the $\mathrm{O}_{\text {zeolite }}$ centres.

ZSM-5 framework provides new efficient adsorption sites for methanol.

Temperature-programmed operando XAS spectra (Fig. 4c and Supplementary Figs. 27 and 28) revealed again the high stability of the framework $\mathrm{Ta}(\mathrm{V})$ sites. No apparent change in oxidation state (edge position) or local environment (EXAFS) under reaction conditions is observed, although the white line intensity is shown to be proportional to temperature. Linear combination fitting of the XANES region reveals a decrease in the degree of methanol adsorption/interaction with increasing reaction temperature (Fig. 4d and Supplementary Fig. 29). Even at reaction temperature, adsorption of methanol at the $\mathrm{Ta}(\mathrm{V})$ site is still apparent, clearly demonstrating the unique interaction between methanol and the $\mathrm{Ta}(\mathrm{V})$ sites under reaction conditions (Fig. $4 \mathrm{~d}$ and Supplementary Fig. 30).

Studies of the reaction mechanism. A combination of INS spectroscopy and DFT calculations ${ }^{35,36}$ were used to investigate the vibrational dynamics of methanol@TaAlS-1(0.013/0.027/1) in operando (Fig. 5a-d, Supplementary Figs. 31-44, Supplementary Tables 18-21; Supplementary Note 4 Inelastic neutron scattering). Comparison of INS spectra of adsorbed methanol and that of solid methanol show a number of differences. Peaks at low energy (below $150 \mathrm{~cm}^{-1}$ ), assigned to the lattice modes of solid $\mathrm{MeOH}$, have become a continuum profile, suggesting that the $\mathrm{MeOH}$ molecules are strongly adsorbed in zeolite pores with heavily hindered motions. The C-O-H deformation $\left(697,778 \mathrm{~cm}^{-1}\right)$ and the $\mathrm{O}-\mathrm{H}$ stretch $\left(3241 \mathrm{~cm}^{-1}\right)$ modes of $\mathrm{Me}-\mathrm{OH}$ groups are both greatly broadened (the weak feature at $\sim 700 \mathrm{~cm}^{-1}$ the tail at $3400 \mathrm{~cm}^{-1}$, respectively) while the methyl deformation $(1162,1454$ $\left.\mathrm{cm}^{-1}\right)$ and the $\mathrm{C}-\mathrm{H}$ stretch modes $\left(2955 \mathrm{~cm}^{-1}\right)$ of the $-\mathrm{CH}_{3}$ group of $\mathrm{MeOH}$ are largely unchanged. Together, these suggest the binding of $-\mathrm{OH}$ group of $\mathrm{MeOH}$ in TaAlS-1 via the interaction with $\mathrm{Ta}(\mathrm{V})$ and Brønsted acid sites, consistent with SXPD and XAS results.

Catalytic conversion at $350^{\circ} \mathrm{C}$ for $20 \mathrm{~min}$ of the adsorbed $\mathrm{MeOH}$ molecules on TaAlS-1 resulted in the spectra marked as "Reacted $\mathrm{MeOH} 1$ " in Fig. $5 \mathrm{a}-\mathrm{c}$. The new feature at $422 \mathrm{~cm}^{-1}$ (assigned as a C-O-C scissoring mode) together with two features at 194 and $245 \mathrm{~cm}^{-1}$ (assigned as methyl torsions), demonstrate the formation of DME. By comparing the INS spectra of solid and adsorbed DME, all these new INS peaks of reacted $\mathrm{MeOH}$ are consistent with that of the latter 

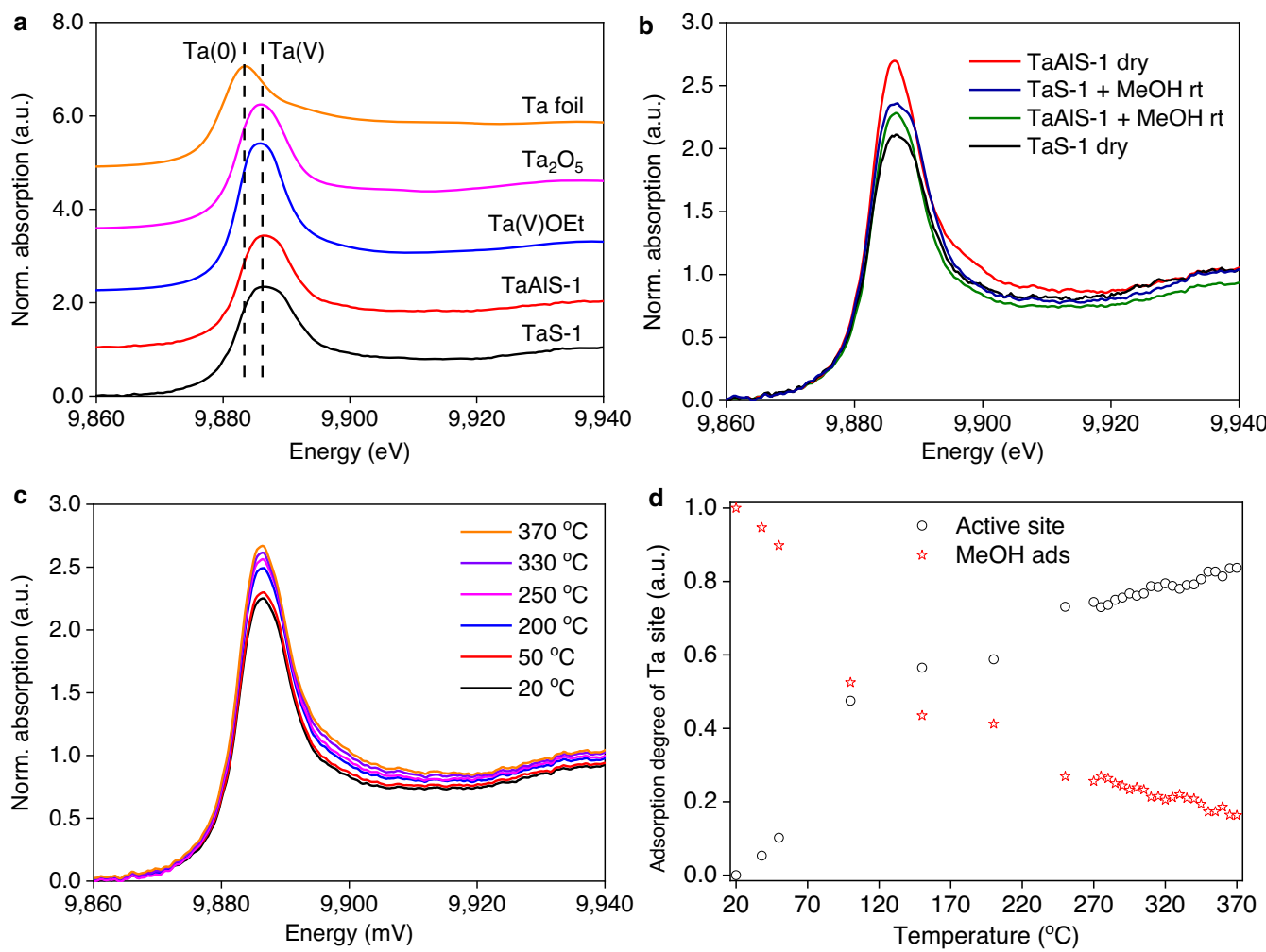

Fig. 4 Ta $L_{3}$-edge X-ray absorption spectroscopy (XAS) for TaAIS-1 zeolite and references. a XANES spectra at the Ta $L_{3}$ edge of Ta foil, Ta(V) references and Ta-zeolites. $\mathbf{b}$ XANES spectra illustrating the influence of methanol adsorption at room temperature on Ta-zeolites. c Operando XANES spectra at the Ta $L_{3}$ edge of TaAIS-1 zeolite during the conversion of methanol, only selected spectra shown. $\mathbf{d}$ Deconvolution of XANES via linear combination fitting to activated and adsorbed species.

(Supplementary Figs. 45-47), indicating that the formed DME readily adsorbs on TaAlS-1. A further reaction was conducted at $370{ }^{\circ} \mathrm{C}$ for $90 \mathrm{~min}$ (spectrum marked as "Reacted $\mathrm{MeOH} 2$ " in Fig. $5 \mathrm{a}-\mathrm{c}$ ). The umbrella mode of TMO was clearly observed at $365 \mathrm{~cm}^{-1}$ (Fig. 5a, d, Supplementary Fig. 34, Supplementary Table 20), indicating that the adsorbed DME is attacked by another $\mathrm{MeOH}$ to form TMO and water; the librational modes of the latter are clearly seen at $500-700 \mathrm{~cm}^{-1}$ (Fig. 5a). Significantly, this represents the first vibrational spectroscopic evidence of the presence of TMO in MTO reactions and is in excellent agreement with the SXPD observation. These results, combined with previous observations by pulsed electron beam high pressure ion source mass spectrometry and $\mathrm{NMR}^{16,37}$, thus support the TMO-mechanism for the formation of the first carbon-carbon bond in MTO reactions.

Simultaneously, a new feature at $221 \mathrm{~cm}^{-1}$ (assigned to the methyl torsion of propene) appears and the $\mathrm{C}=\mathrm{C}-\mathrm{C}$ scissoring $\left(429 \mathrm{~cm}^{-1}\right), \mathrm{C}=\mathrm{CH}_{2}$ rocking $\left(916 \mathrm{~cm}^{-1}\right),=\mathrm{CH}-$ rocking $(1289$ $\left.\mathrm{cm}^{-1}\right)$ and $\mathrm{C}=\mathrm{C}$ stretching $\left(1644 \mathrm{~cm}^{-1}\right)$ modes of propene are all observed, demonstrating the formation of carbon-carbon bonds required for the product, propene. Additional new INS features at $1044,1161,1371,1453$ and $2972 \mathrm{~cm}^{-1}$ are fully consistent with the formation of propene (Supplementary Figs. 48-50).

A complete catalytic cycle based upon the structural, dynamic and modelling results for the MTO reaction over TaAlS-1 is established (Fig. 5e). In TaAlS-1, strong adsorption of methanol occurs on $\mathrm{Ta}(\mathrm{V})$ and Brønsted acid sites. The latter reacts with one weakly adsorbed methanol molecule to form DME, which reacts with a third methanol molecule on a Brønsted acid site to form TMO as a key intermediate. The TMO is then reacted with an activated methanol molecule on $\mathrm{Ta}(\mathrm{V})$ site to form the first carbon-carbon bond (Fig. 5e). This has been confirmed by temperature-programmed mass spectroscopy, where adsorbed TMO species within TaAlS- 1 reacted with deuterated methanol, $\mathrm{CD}_{3} \mathrm{OD}$, to yield partially deuterated propene, $\mathrm{C}_{3} \mathrm{H}_{3} \mathrm{D}_{3}$ (Supplementary Note 5 Temperature-programmed mass spectroscopy, Supplementary Figs. 51 and 52). By contrast, on HZSM-5, the formation of both intermediates and propene proceed solely on the Brønsted acid sites (Fig. $5 \mathrm{f})^{16}$. After the induction period, the reaction over TaAlS-1 mainly proceeds via the alkene cycle to produce propene selectively, while on HZSM-5, the aromatic cycle dominates the reaction network to produce ethene as well as

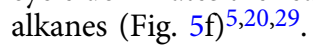

\section{Discussion}

The sustainable production of propene will reduce our reliance on fossil fuels. Powerful drivers exist to optimise the product selectivity and catalytic stability in the complex MTO process to mitigate the projected global propene shortage. The new heteroatomic zeolite TaAlS-1 integrates $\mathrm{Ta}(\mathrm{V})$ and $\mathrm{Al}(\mathrm{III})$ sites into the MFI-zeolite framework for the first time and shows a new distribution of active sites compared to conventional HZSM-5 materials. TaAlS-1 shows remarkable performance in converting methanol to propene. Ta(V) sites in the TaAlS-1 framework have two vital roles: (i) promoting the adsorption and activation of methanol, in cooperation with Brønsted acid sites, to drive the formation of TMO and sequentially carbon-carbon bonds; (ii) optimising the acidity of the zeolite so as to hinder the aromatic cycle and to restrict hydrogen transfer to minimise the formation of ethene, alkanes and coke. The product obtained from the flowreactor contains primarily light olefins (85\%) with only a small amount of alkanes (6.9\%). Thus, huge energy savings can be potentially gained from the challenging alkene-alkane separation 

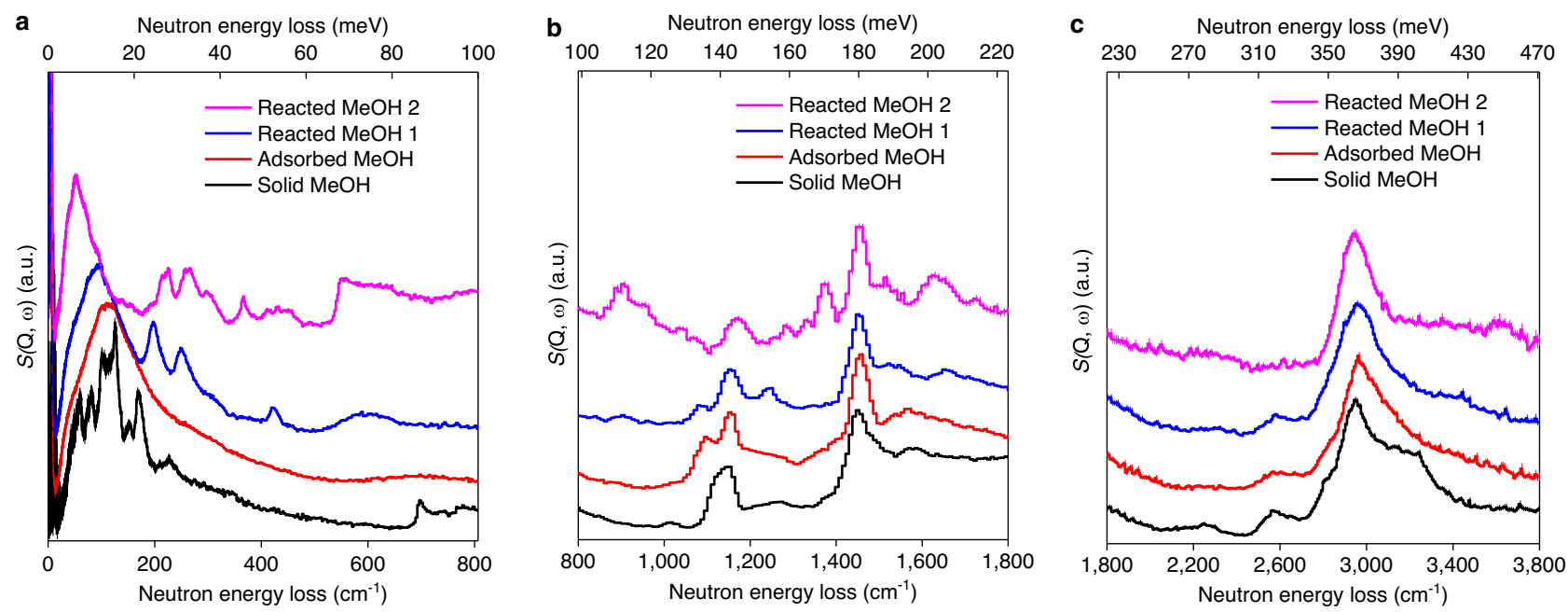

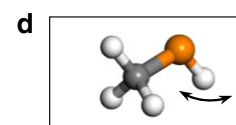

$697 \mathrm{~cm}^{-1}$

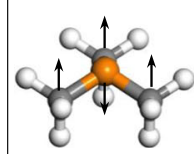

$365 \mathrm{~cm}^{-1}$

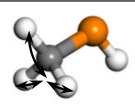

$1162 \mathrm{~cm}^{-1}$

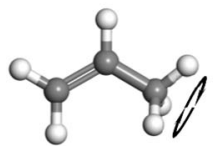

$221 \mathrm{~cm}^{-1}$

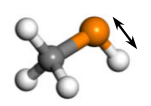

$3241 \mathrm{~cm}^{-1}$

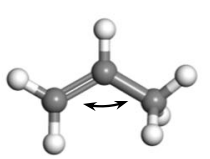

$429 \mathrm{~cm}^{-1}$

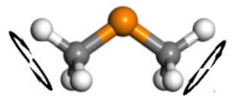

$194 \mathrm{~cm}^{-1}$

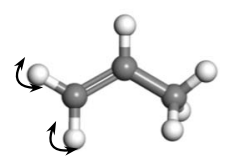

$916 \mathrm{~cm}^{-1}$
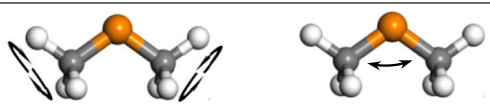

$422 \mathrm{~cm}^{-1}$

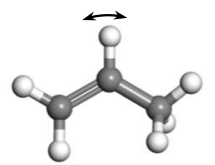

$1289 \mathrm{~cm}^{-1}$

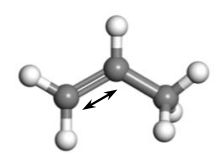

$1644 \mathrm{~cm}^{-1}$
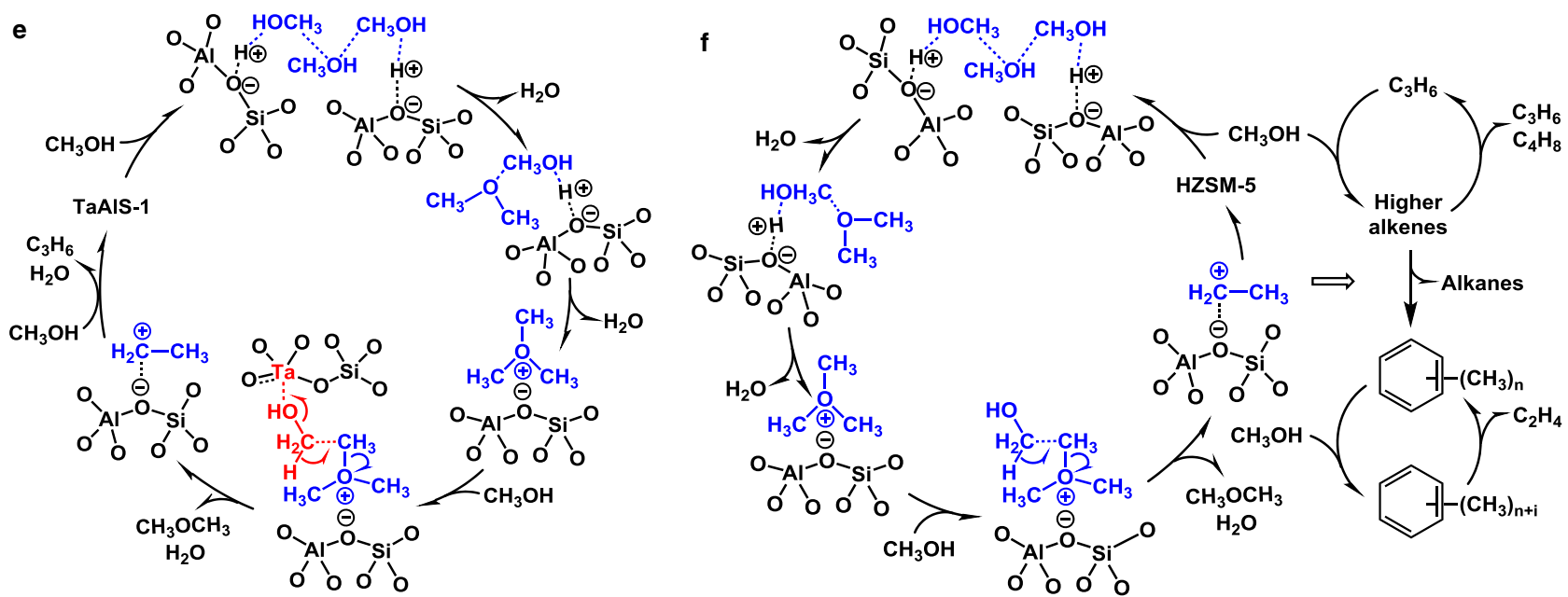

Fig. 5 Inelastic neutron scattering (INS) spectra for TaAIS-1(0.013/0.027/1) on the adsorption and catalytic conversion of methanol and proposed reaction mechanism. All spectra shown here are difference spectra. Full spectra are shown in the SI. The INS spectra of reactant, intermediates and products were recorded and modelled via DFT calculations, allowing a full assignment of the spectral features. Where no error bars are visible these are smaller than the symbols used to represent the data points. Comparison of INS spectra obtained at TOSCA (a), at MAPS (b) at incident energy 250 meV over the momentum transfer range $0 \AA^{-1} \leq Q \leq 9 \AA^{-1}$ and, at MAPS (c) at incident energy 650 meV over the momentum transfer range $0 \AA^{-1} \leq Q \leq 9 \AA^{-1}$ for condensed solid methanol, adsorbed methanol, and reacted methanol on TaAIS-1(0.013/0.027/1). d Selected vibrational modes of methanol, DME, TMO and propene ( $\mathrm{C}$, grey; $\mathrm{O}$, orange; $\mathrm{H}$, white). Proposed reaction mechanism for the conversion of methanol in the induction period over e TaAIS-1 based on INS/SXPD experiments and $\mathbf{f}$ in the induction and dual-cycle period over HZSM-5 based on SXPD and literature reports ${ }^{16,20}$.

(e.g., the difference in boiling points of propene and propane is $5.6^{\circ} \mathrm{C}$ ) compared with the product that contains mostly alkanes over HZSM-5. Similarly, the high P/E ratio obtained from TaAlS1 will also simplify the downstream separation of propene from ethene. TaAlS- 1 is highly stable, and the synthesis of TaAlS-1 could readily be scaled up using the existing infrastructure for synthesising ZSM-5, further demonstrating its potential in these challenging industrial processes.

\section{Methods}

Catalyst preparation. HZSM- 5 samples were obtained by calcining $\mathrm{NH}_{4}-\mathrm{ZSM}-5$ at $550{ }^{\circ} \mathrm{C}$ under air flow for $14 \mathrm{~h}$, and denoted as $\mathrm{HZSM}-5$ (Al/Si mole ratio). $\mathrm{NH}_{4-}^{-}$ ZSM-5 samples were purchased from Alfa Aesar. TaAlS-1 and TaS-1 samples were prepared by hydrothermal reactions and denoted as TaAlS-1(Ta/Al/Si mole ratio) and $\mathrm{TaS}-1(\mathrm{Ta} / \mathrm{Si}$ mole ratio), respectively. In a typical synthesis, aluminium isopropoxide ( $99.99+\%$, Sigma Aldrich) was first dissolved in deionised water, into which tetrapropylammonium hydroxide solution (TPAOH, $1.0 \mathrm{M}$ in $\mathrm{H}_{2} \mathrm{O}$, Sigma Aldrich) as the structure-directing agent was added. After the mixture was stirred at room temperature for $2 \mathrm{~h}$, tantalum ethoxide $\left(99.999 \%\right.$ metals basis, Alfa Aesar $\left.{ }^{\mathrm{m}}\right)$ 
was added and the mixture was stirred for another $2 \mathrm{~h}$. Then tetraethyl orthosilicate ( $98 \%$, Sigma Aldrich) was added dropwise and the mixture was stirred for another $2 \mathrm{~h}$, resulting in a gel with a chemical composition of $1 \mathrm{Si}: x \mathrm{Al}: y \mathrm{Ta}: 0.25 \mathrm{~T}-$ PAOH: $15 \mathrm{H}_{2} \mathrm{O}$ ( $x$ and $y$ were determined by the target $\mathrm{Al} / \mathrm{Si}$ and $\mathrm{Ta} / \mathrm{Si}$ mole ratios, respectively). The gel was transferred into a $46-\mathrm{mL}$ Teflon-lined stainless-steel autoclave, which was sealed and heated at $170^{\circ} \mathrm{C}$ for $48 \mathrm{~h}$. The solid products were centrifuged, washed with deionised water, dried overnight at $80^{\circ} \mathrm{C}$, and finally calcined at $550^{\circ} \mathrm{C}$ under an air flow for $14 \mathrm{~h}$. TaS- 1 samples were synthesised by the same procedure but without the addition of aluminium isopropoxide. The typical yields of all zeolites in this study are $90-95 \%$.

Catalytic testing. Catalytic reactions were carried out in a stainless steel continuous-flow reactor (12.7 $\mathrm{mm}$ i.d.). Two grams of catalyst was pressed, crushed, and sorted into grains by $40-60$ meshes, which were then activated at $550^{\circ} \mathrm{C}$ for $3 \mathrm{~h}$ under a flow of nitrogen before the reaction. Methanol was injected into the nitrogen flow $\left(\mathrm{N}_{2} /\right.$ methanol mole ratio: 18.5) by syringe pump (Cole-Parmer) and passed through the reactor at the target temperature. The output liquid products were collected and analysed by gas chromatography (Agilent 7890B, equipped with an HP-5 column $30 \mathrm{~m} \times 0.32 \mathrm{~mm} \times 0.25 \mu \mathrm{m})$ and gas chromatography-mass spectrometry (GC-MS) (Agilent 6890N-Agilent 5973N, equipped with an HP5 MS column $30 \mathrm{~m} \times 0.25 \mathrm{~mm} \times 0.25 \mu \mathrm{m})$. The output gas products were collected and analysed by GC (Agilent Micro GC 490 equipped with a PoraPLOT U column, length $10 \mathrm{~m}$ ) and GC-MS (Agilent 7890A-Agilent 5975C, equipped with an HPPLOT/Q column $30 \mathrm{~m} \times 0.53 \mathrm{~mm} \times 40 \mu \mathrm{m})$. Methanol conversion was calculated by using Eq. (1):

$$
\mathrm{MeOH} \text { conversion }=\left\{\left(\mathrm{MeOH}_{\text {in }}-\mathrm{MeOH}_{\text {out }}\right) / \mathrm{MeOH}_{\text {in }}\right\} \times 100 \%
$$

where $\mathrm{MeOH}_{\text {in }}$ and $\mathrm{MeOH}_{\text {out }}$ denote the moles of $\mathrm{MeOH}$ in the feed and exit, respectively. Product selectivity was calculated on a carbon basis using Eq. (2):

$$
S_{i}=\left\{\left(a_{i} \times n_{i}\right) /\left(\sum a_{i} \times n_{i}\right)\right\} \times 100 \%
$$

where $a_{i}$ and $n_{i}$ denote the carbon number and number of moles of product $i$, respectively.

X-ray absorption spectroscopy. Transmission $\mathrm{Ta}_{\mathrm{L}}$-edge turbo-X-ray absorption spectra were collected at the I20 beamline at the Diamond Light Source, employing non-monochromatic X-rays produced by a bent crystal polychromator and fast moving exit slits to enable a scan collection time of $4 \mathrm{~s}$. Data collection spanned $200 \mathrm{eV}$ before the edge to $1000 \mathrm{eV}$ above it, with a step size of $0.3 \mathrm{eV}$; for the energy calibration a Ta foil reference sample was used. Data processing was carried out in the Demeter open source software package (version 0.9.26) with XAS spectra processing (normalisation and background subtractions) and linear combination fitting conducted within the Athena programmes. Reference spectrum of tantalum (V) ethoxide was collected in the liquid phase and $\mathrm{Ta}_{2} \mathrm{O}_{5}$ standards were collected after dilution in boron nitride. For temperature-programmed operando turbo-XAS experiments, $18 \mathrm{mg}$ zeolite was loaded in a Harrick Praying Mantis cell. After zeolite activation at $550^{\circ} \mathrm{C}$ and cooling the cell to room temperature, methanol was introduced via a Dreschel bottle with an $\mathrm{N}_{2}$ carrier gas (flow rate $1 \mathrm{~mL} \mathrm{~min}^{-1}$ ). Methanol was bubbled with a $\mathrm{N}_{2}$ flow into the cell at $1 \mathrm{~mL} \mathrm{~min}^{-1}$. The cell was heated at $10^{\circ} \mathrm{C} \mathrm{min}-1$ from room temperature to $200^{\circ} \mathrm{C}$, then increased to $370{ }^{\circ} \mathrm{C}$ at $2^{\circ} \mathrm{C} \mathrm{min}^{-1}$. The XAS spectra were recorded and the exhaust was analysed by an on-line mass spectrometry.

High-resolution SXPD and Rietveld refinement. SXPD data were collected on beamline I11 (Diamond Light Source, UK) using a wavelength of $0.82487(1) \AA$ at room temperature. The zeolite powder was loaded into a $0.7 \mathrm{~mm}$ borosilicate glass capillary. High-resolution diffraction data were obtained from the samples using the multi-analyser crystal (MAC) detectors. The patterns were collected in the $2 \theta$ range $0-150^{\circ}$ with $0.001^{\circ}$ data step. Using the TOPAS software, the SXPD patterns were refined by the Rietveld method. The Thompson-Cox-Hastings pseudo-Voigt peak function ${ }^{38}$ was applied to describe the diffraction peaks. The scale factor and lattice parameters were allowed to refine for all diffraction patterns. The refined structural parameters include the fractional coordinates $(x, y, z)$ and isotropic displacement factors (Beq) for all atoms, and the site occupancy factors (SOF) for all Ta, Al, Si species and methanol. The Beq values for all framework T sites and $\mathrm{O}$ sites are each refined with the same value. The quality of the Rietveld refinements has been assured by low goodness-of-fit (gof) factors, low weighted profile factors (Rwp) and well-fitted patterns with reasonable Beq that are within experimental errors. The crystallographic data (reference number CCDC-2022750-2022754) and refinement details are summarised in Supplementary Tables 6-13.

Inelastic neutron scattering. INS spectra were recorded on the TOSCA ${ }^{39}$ and MAPS $^{40}$ spectrometers at the ISIS Facility at the STFC Rutherford Appleton Laboratory (UK), as well as the VISION spectrometer at the Spallation Neutron Source, Oak Ridge National Laboratory (USA). Both TOSCA and VISION are indirect geometry crystal analyser instruments while MAPS is a direct-geometry inelastic spectrometer. The two types of instrument are complementary: TOSCA and VISION provide high-resolution spectra in the $0-2000 \mathrm{~cm}^{-1}$ range, MAPS provides access to the medium to high energy range $\left(800-4000 \mathrm{~cm}^{-1}\right)$ with good resolution. All the INS spectra were collected after the sample was cooled and stabilised at temperatures below $15 \mathrm{~K}$.

The adsorption/reaction experiments were conducted at the TOSCA and MAPS beamlines. In a typical experiment, the catalyst $(\sim 11 \mathrm{~g})$ was loaded into a flow-type Inconel cell ${ }^{41}$ that can also be used as a static cell with all valves closed. The sample was heated at $450{ }^{\circ} \mathrm{C}\left(5^{\circ} \mathrm{C} \mathrm{min}-1\right.$ ramp rate $)$ under $\mathrm{He}$ for $3 \mathrm{~h}$ to remove any remaining trace water before the experiment. Then $30 \mathrm{mmol} \mathrm{MeOH}$ was injected into the cell at $25^{\circ} \mathrm{C}$. Before the data collection, the cell was flushed using dry He to remove weakly bound $\mathrm{MeOH}$. The samples were cooled to $<15 \mathrm{~K}$ before data collection. After each reaction, the cell was quenched in liquid nitrogen for INS collection to detect the presence of possible reaction intermediates. INS spectra of pure solid compounds for both starting material and reaction products were collected at $5 \mathrm{~K}$. For measurements on MAPS, the samples were immediately and quickly transferred to an aluminium-can in a glovebox after reaction was quenched in liquid nitrogen. All MAPS spectra were recorded using the high-resolution A-chopper package at incident energies of 250 and $650 \mathrm{meV}$, with frequencies of 400 and $600 \mathrm{~Hz}$, respectively. The MAPS spectra were integrated over a momentum transfer $(Q)$ range of $0 \leq Q \leq 9 \AA^{-1}$ to minimise overtone contributions present at higher $Q$ values.

\section{Data availability}

The raw time-of-flight TOSCA and MAPS spectra are available from: https://doi.org/ 10.5286/ISIS.E.RB1910009 and https://doi.org/10.5286/ISIS.E.RB2010255, respectively. The crystal structures are available free of charge from the Cambridge Crystallographic Data Centre under reference number CCDC-2022750-2022754. All relevant data are available from the corresponding authors, and/or are included with the manuscript.

Received: 18 September 2020; Accepted: 12 January 2021; Published online: 05 February 2021

\section{References}

1. Galvis, H. M. T. et al. Supported iron nanoparticles as catalysts for sustainable production of lower olefins. Science 335, 5 (2012).

2. Alper, J. in The Changing Landscape of Hydrocarbon Feedstocks for Chemical Production: Implications for Catalysis: Proceedings of a Workshop at NAP.edu. (The National Academies Press, Washington, DC, 2016).

3. Towfighi, J., Zimmermann, H., Karimzadeh, R. \& Akbarnejad, M. M. Steam cracking of naphtha in packed bed reactors. Ind. Eng. Chem. Res. 41, 1419-1424 (2002)

4. Grant, J. T. et al. Selective oxidative dehydrogenation of propane to propene using boron nitride catalysts. Science 354, 1570-1573 (2016).

5. Yarulina, I., Chowdhury, A. D., Meirer, F., Weckhuysen, B. M. \& Gascon, J. Recent trends and fundamental insights in the methanol-to-hydrocarbons process. Nat. Catal. 1, 398-411 (2018).

6. Yarulina, I. et al. Structure-performance descriptors and the role of Lewis acidity in the methanol-to-propylene process. Nat. Chem. 10, 804-812 (2018).

7. Bailleul, S. et al. A supramolecular view on the cooperative role of Brønsted and Lewis acid sites in zeolites for methanol conversion. J. Am. Chem. Soc. 141, 14823-14842 (2019).

8. Li, C. et al. Synthesis of reaction-adapted zeolites as methanol-to-olefins catalysts with mimics of reaction intermediates as organic structure-directing agents. Nat. Catal. 1, 547-554 (2018).

9. Yang, M. et al. High propylene selectivity in methanol conversion over a small-pore SAPO molecular sieve with ultra-small cage. ACS Catal. 10, 3741-3749 (2020)

10. Tian, P., Wei, Y., Ye, M. \& Liu, Z. Methanol to olefins (MTO): from fundamentals to commercialization. ACS Catal. 5, 1922-1938 (2015).

11. Zhao, X. et al. Investigation of methanol conversion over high-Si beta zeolites and the reaction mechanism of their high propene selectivity. Catal. Sci. Technol. 7, 5882-5892 (2017).

12. Arora, S. S., Nieskens, D. L. S., Malek, A. \& Bhan, A. Lifetime improvement in methanol-to-olefins catalysis over chabazite materials by high-pressure $\mathrm{H}_{2}$ cofeeds. Nat. Catal. 1, 666-672 (2018).

13. Olah, G. A. Towards oil independence through renewable methanol chemistry. Angew. Chem. Int. Ed. 52, 104-107 (2013).

14. Wang, W., Buchholz, A., Seiler, M. \& Hunger, M. Evidence for an initiation of the methanol-to-olefin process by reactive surface methoxy groups on acidic zeolite catalysts. J. Am. Chem. Soc. 125, 15260-15267 (2003).

15. Hutchings, G. J., Gottschalk, F., Hall, M. V. M. \& Hunter, R. Hydrocarbon formation from methylating agents over the zeolite catalyst ZSM-5. Comments on the mechanism of carbon-carbon bond and methane formation. J. Chem. Soc. Faraday 83, 571-583 (1987).

16. $\mathrm{Wu}, \mathrm{X}$. et al. Direct mechanism of the first carbon-carbon bond formation in the methanol-to-hydrocarbons process. Angew. Chem. Int. Ed. 56, 9039-9043 (2017). 
17. Li, J. et al. A route to form initial hydrocarbon pool species in methanol conversion to olefins over zeolites. J. Catal. 317, 277-283 (2014).

18. Chowdhury, A. D. et al. Initial carbon-carbon bond formation during the early stages of the methanol-to-olefin process proven by zeolite-trapped acetate and methyl acetate. Angew. Chem. Int. Ed. 55, 15840-15845 (2016).

19. Comas-Vives, A., Valla, M., Copéret, C. \& Sautet, P. Cooperativity between $\mathrm{Al}$ sites promotes hydrogen transfer and carbon-carbon bond formation upon dimethyl ether activation on alumina. ACS Cent. Sci. 1, 313-319 (2015).

20. Olsbye, U. et al. Conversion of methanol to hydrocarbons: how zeolite cavity and pore size controls product selectivity. Angew. Chem. Int. Ed. 51, 5810-5831 (2012).

21. Yoshioka, M., Yokoi, T. \& Tatsumi, T. Development of the CON-type aluminosilicate zeolite and its catalytic application for the MTO reaction. ACS Catal. 5, 4268-4275 (2015)

22. Lin, L. et al. Quantitative production of butenes from biomass-derived $\gamma$ valerolactone catalysed by hetero-atomic MFI zeolite. Nat. Mater. 19, 86-93 (2020).

23. Vidal, V., Théolier, A., Thivolle-Cazat, J. \& Basset, J.-M. Metathesis of alkanes catalyzed by silica-supported transition metal hydrides. Science 276, 99-102 (1997).

24. Hartmann, M., Ernst, S., Prakash, A. M. \& Kevan, L. Characterization of mesoporous and microporous molecular sieves containing niobium and tantalum. Stud. Surf. Sci. Catal. 129, 201-208 (2000).

25. Haas, D. A., Mailer, C. \& Robinson, B. H. Using nitroxide spin labels. How to obtain Tle from continuous wave electron paramagnetic resonance spectra at all rotational rates. Biophys. J. 64, 594-604 (1993).

26. Wichterlová, B., Nováková, J. \& Prášil, Z. Structure of defects in $\gamma$-irradiated ZSM-5 and Y zeolites: an esr study. Zeolites 8, 117-121 (1988).

27. Svelle, S. et al. Conversion of methanol into hydrocarbons over zeolite $\mathrm{H}-$ ZSM-5: ethene formation is mechanistically separated from the formation of higher alkenes. J. Am. Chem. Soc. 128, 14770-14771 (2006).

28. Müller, S. et al. Hydrogen transfer pathways during zeolite catalyzed methanol conversion to hydrocarbons. J. Am. Chem. Soc. 138, 15994-16003 (2016).

29. Westgård Erichsen, M., Svelle, S. \& Olsbye, U. The influence of catalyst acid strength on the methanol to hydrocarbons (MTH) reaction. Catal. Today 215, 216-223 (2013).

30. Lo, B. T. W. et al. Elucidation of adsorbate structures and interactions on Brønsted acid sites in H-ZSM- 5 by synchrotron X-ray powder diffraction. Angew. Chem. Int. Ed. 55, 5981-5984 (2016).

31. Lemishko, T., Valencia, S., Rey, F., Jiménez-Ruiz, M. \& Sastre, G. Inelastic neutron scattering study on the location of Brønsted acid sites in high silica LTA zeolite. J. Phys. Chem. C 120, 24904-24909 (2016).

32. Lemishko, $T$. et al. Inelastic neutron scattering study of the aluminum and Brønsted site location in aluminosilicate LTA zeolites. J. Phys. Chem. C 122, 11450-11454 (2018).

33. Corma, A., Llabrés i Xamena, F. X., Prestipino, C., Renz, M. \& Valencia, S. Water resistant, catalytically active $\mathrm{Nb}$ and $\mathrm{Ta}$ isolated Lewis acid sites, homogeneously distributed by direct synthesis in a Beta zeolite. J. Phys. Chem. C 113, 11306-11315 (2009).

34. Wedig, A. et al. Nanoscale cation motion in $\mathrm{TaO}_{x}, \mathrm{HfO}_{x}$ and $\mathrm{TiO}_{x}$ memristive systems. Nat. Nanotechnol. 11, 67-74 (2016).

35. Suwardiyanto et al. An assessment of hydrocarbon species in the methanol-tohydrocarbon reaction over a ZSM-5 catalyst. Faraday Discuss. 197, 447-471 (2017).

36. O'Malley, A. J. et al. Room temperature methoxylation in zeolites: insight into a key step of the methanol-to-hydrocarbons process. Chem. Commun. 52, 2897-2900 (2016).

37. Grimsrud, E. P. \& Kebarle, P. Gas phase ion equilibriums studies of the hydrogen ion by methanol, dimethyl ether, and water. Effect of hydrogen bonding. J. Am. Chem. Soc. 95, 7939-7943 (1973).

38. Thompson, S. P. et al. Beamline I11 at diamond: a new instrument for high resolution powder diffraction. Rev. Sci. Instrum. 80, 075107 (2009).

39. Pinna, R. S. et al. The neutron guide upgrade of the TOSCA spectrometer. Nucl. Instrum. Methods Phys. Res. Sect. A 896, 68-74 (2018).

40. Ewings, R. A. et al. Upgrade to the MAPS neutron time-of-flight chopper spectrometer. Rev. Sci. Instrum. 90, 035110 (2019).

41. Silverwood, I. P. et al. Experimental arrangements suitable for the acquisition of inelastic neutron scattering spectra of heterogeneous catalysts. Rev. Sci. Instrum. 82, 034101 (2011).

\section{Acknowledgements}

We thank EPSRC (EP/P011632/1), the Royal Society, National Natural Science Foundation of China (21733011, 21890761, 21673076), and the University of Manchester for funding. We thank EPSRC for funding and the EPSRC National Service for EPR Spectroscopy at Manchester. A.M.S. is supported by a Royal Society Newton International Fellowship. We are grateful to the STFC/ISIS Facility, Oak Ridge National Laboratory (ORNL) and Diamond Light Source (DLS) for access to the beamlines TOSCA/MAPS, VISION and I11/I20, respectively. We acknowledge Dr. L. Keenan for help at I20 beamline (SP23594-1). UK Catalysis Hub is kindly thanked for resources and support provided via our membership of the UK Catalysis Hub Consortium and funded by EPSRC grant: EP/R026939/1, EP/ R026815/1, EP/R026645/1, EP/R027129/1 or EP/M013219/1 (biocatalysis). We acknowledge the support of The University of Manchester's Dalton Cumbrian Facility (DCF), a partner in the National Nuclear User Facility, the EPSRC UK National Ion Beam Centre and the Henry Royce Institute. We recognise Dr. R. Edge and Dr. K. Warren for their assistance during the ${ }^{60} \mathrm{Co} \gamma$-irradiation processes. We thank Prof. A. Jentys from the Technical University of Munich for the measurement of the INS spectrum of iso-butene. We thank C. Webb, E. Enston and G. Smith for help with GC-MS; Dr. L. Hughes for help with SEM and EDX; M. Kibble for help at TOSCA/MAPS beamlines. Computing resources (time on the SCARF compute cluster for some of the CASTEP calculations) was provided by STFC's e-Science facility. A portion of this research used resources at the Spallation Neutron Source, a DOE Office of Science User Facility operated by ORNL. The computing resources at ORNL were made available through the VirtuES and the ICE-MAN projects, funded by Laboratory Directed Research and Development programme and Compute and Data Environment for Science (CADES).

\section{Author contributions}

L.L., M.F. and M.P.A. carried out syntheses and characterisation of the zeolite samples L.L., X.H. and B.H. carried out catalytic tests and analysis. L.L., A.M.S., F.T. and E.J.L.M collected and analysed EPR data. L.L. and C.M.A.P. collected and analysed the XAS data. L.L., J.H.C., I.D.S., and C.C.T. collected and analysed the SXPD data. Z.T. and Y.L. collected and analysed the Py-IR data. G.S. calculated $\mathrm{Si}\left(Q^{n}\right)$ types. L.L., S.R., S.F.P., H.C., Y.C, L.L.D., and A.J.R.-C. collected and analysed the neutron scattering data and carried out DFT modelling. S.Y. was responsible for the overall direction of the project. L.L. and S.Y. prepared the manuscript with contributions from all authors.

\section{Competing interests}

The authors declare no competing interests.

\section{Additional information}

Supplementary information The online version contains supplementary material available at https://doi.org/10.1038/s41467-021-21062-1.

Correspondence and requests for materials should be addressed to S.Y.

Peer review information Nature Communications thanks Vadim Sikolenko, and the other, anonymous, reviewer(s) for their contribution to the peer review of this work. Peer reviewer reports are available.

Reprints and permission information is available at http://www.nature.com/reprints

Publisher's note Springer Nature remains neutral with regard to jurisdictional claims in published maps and institutional affiliations.

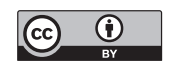

Open Access This article is licensed under a Creative Commons Attribution 4.0 International License, which permits use, sharing, adaptation, distribution and reproduction in any medium or format, as long as you give appropriate credit to the original author(s) and the source, provide a link to the Creative Commons license, and indicate if changes were made. The images or other third party material in this article are included in the article's Creative Commons license, unless indicated otherwise in a credit line to the material. If material is not included in the article's Creative Commons license and your intended use is not permitted by statutory regulation or exceeds the permitted use, you will need to obtain permission directly from the copyright holder. To view a copy of this license, visit http://creativecommons.org/ licenses/by/4.0/.

(C) The Author(s) 2021 